\title{
Non-specific aorto-arteriitis involving abdominal aorta branches in an adolescent girl (clinical case)
}

\author{
Galina Glazyrina \\ From 21st European Pediatric Rheumatology (PReS) Congress \\ Belgrade, Serbia. 17-21 September 2014
}

\section{Introduction}

In children, the Takajasu arteriitis is one of the most frequent causes of renovascular hypertension.

\section{Objectives}

To present a clinical case on non-specific aorto-arteriitis involving abdominal aorta branches in an adolescent girl.

\section{Methods}

Patient Dina Zh., female, 14 years old.

The patient was admitted to the Department of cardiology and rheumatology of Chelyabinsk regional paediatric hospital on January 15, 2014. Fatigue, dyspnoe, headache, skin rash, BP increase up to $160 / 100 \mathrm{~mm} \mathrm{hg}$ were reported. Severe disease was reported upon hospitalization; justification: Polyserositis: bilateral focal pleuropneumonia, class 2 respiratory failure, pancarditis (endomyopericarditis), class 2 heart failure, peritoneal exudation. Treatment resulted in stabilization; heart failure and respiratory failure symptoms were managed.

Treatment - arterial hypertension (130/80 - 160/ $110 \mathrm{~mm} \mathrm{hg}$ ) persisted. Pink - to purple livedo- like rash appeared on the lower extremities and abdominal wall. Proteinuria (daily loss up to $310 \mathrm{mg}$ ) was reported; diuresis level $-1350 \mathrm{ml} /$ day. At hospitalization Day 3 hypertension attack was reported; it included BP increase up to 190/ $110 \mathrm{~mm} / \mathrm{hg}$, severe headache, spoor progressing to loss of consciousness, and seizures. CT of abdominal cavity with aortography: manifested narrowing of celiac trunk proximal regions, narrowing of superior mesenteric artery isthmus, narrowing of dextral renal artery. Blood circulation was not detected in proximal regions of the sinister renal artery. Inferior mesenteric artery: no significant changes reported.

\footnotetext{
Hospital Pediatrics, South Ural State Medical University, chelyabinsk, Russian
} Federation

\section{Results}

Treatment: pulse treatment with cyclophosphane (15 mg/kg dose), prednisolone (60 mg/day, $\mathrm{i} / \mathrm{m}$ injections), anti-hypertension treatment, anti - aggregation treatment. Due to presence of abdominal aorta branches, critical stenosis the patient was transferred to the Federal centre of cardiovascular surgery of Chelyabinsk. Operation: stunting of the affected arteries; sinister renal artery angioplastics. No complications were reported during the post-operation period. Improvements were reported, including recovery of consciousness, and BP normalization; the patient resumed oral feeding, and manifestations of heart failure were managed. The patient's condition has improved; the girl was active. Normal blood pressure and no complaints were reported. The patient demonstrated normal appetite; weight gain was reported. US imaging: recovery of renal circulation was reported. Treatment was continued: methylprednisolone (16 mg/day), methotrexate (12.5 mg/day), folic acid ( $1 \mathrm{mg} /$ day), brilinta $(180 \mathrm{mg} /$ day), nifedipine $(20 \mathrm{mg} /$ day). The patient was discharged on March 14, 2013; satisfactory health status was reported.

\section{Conclusion}

This case was associated with affection of abdominal aorta branches (renal arteries, celiac trunk, and superior mesenteric artery); thoracic and abdominal aortas were not involved. Latent disease progressed to manifestation phase after the development of arterial stenosis; development of the hypertension attack required emergency surgical intervention (stunting and angioplastics). Disease outcome was good.

Diagnosis: non-specific aorto-arteriitis (disease of Takajasu), stenosis type 2 involving celiac trunk, superior
mesenteric artery, and renal arteries; secondary arterial hypertension, symptomatic epileptic seizures. 


\section{Disclosure of interest}

None declared.

Published: 17 September 2014

doi:10.1186/1546-0096-12-S1-P157

Cite this article as: Glazyrina: Non-specific aorto-arteriitis involving

abdominal aorta branches in an adolescent girl (clinical case). Pediatric

Rheumatology 2014 12(Suppl 1):P157.

Submit your next manuscript to BioMed Central and take full advantage of:

- Convenient online submission

- Thorough peer review

- No space constraints or color figure charges

- Immediate publication on acceptance

- Inclusion in PubMed, CAS, Scopus and Google Scholar

- Research which is freely available for redistribution 